\title{
Ginsenoside Rh1 inhibits colorectal cancer cell migration and invasion in vitro and tumor growth in vivo
}

\author{
$\mathrm{XI} \mathrm{LYU}^{1}$, XIAODONG XU ${ }^{2}$, AILIN SONG ${ }^{1}$, JINYI GUO $^{1}$, YAWU ZHANG ${ }^{2}$ and YOUCHENG ZHANG ${ }^{2}$ \\ ${ }^{1}$ The Sixth Department of General Surgery and ${ }^{2}$ The Second Department of General Surgery, \\ Lanzhou University Second Hospital, Lanzhou, Gansu 730030, P.R. China
}

Received September 30, 2018; Accepted June 5, 2019

DOI: $10.3892 / \mathrm{ol} .2019 .10742$

\begin{abstract}
Colorectal cancer (CRC) is the third leading cause of cancer-associated mortality worldwide. Ginsenoside Rh1 (Rh1) is a traditional medicine monomer with antitumor activity; however, the effects of Rh1 in CRC remain to be determined. In the present study, SW620 cells were treated with different concentrations of Rh1. Cell Counting Kit-8, wound healing and Transwell assays were performed to measure cell viability and proliferation, migration and invasion, respectively. Subsequently, the mRNA expression levels of matrix metallopeptidase (MMP)1, MMP3 and tissue inhibitor of metalloproteinases 3 (TIMP3) were detected by reverse transcription-quantitative PCR analysis. In addition, the protein expression levels of MMP1, MMP3, TIMP3, and total or phosphorylated (p-)ERK1/2, P38, JNK were detected by western blotting. Furthermore, tumor growth was examined in a nude mouse xenograft model. The results of the present study indicated that Rh1 was not toxic to $\mathrm{CRC}$ cells at various concentrations $(0,50$ or $100 \mu \mathrm{M})$ and treatment durations ( 24 or 48 h). However, cell proliferation was suppressed by Rh1 in a dose-dependent manner. Rh1 (100 $\mu \mathrm{M})$ significantly inhibited cell migration and invasion in vitro. Additionally, Rh1 suppressed the mRNA and protein expression of MMP1 and MMP3, and promoted TIMP3 expression. Rh1 decreased the ratios of p-P38/P38, p-ERK1/2/ERK1-2 and p-JNK/JNK in vitro and in vivo, which suggested that Rh1 inactivated the mitogen-activated protein kinase (MAPK) signaling pathway. Notably, Rh1 markedly decreased tumor volume and weight in vivo. In conclusion, the present study demonstrated that Rh1 inhibited the proliferation, migration and invasion of CRC cells in vitro and tumor growth in vivo. This inhibition was at least partially due to the inhibition of MMP1 and MMP3 expression, the increase in TIMP3 expression level and the
\end{abstract}

Correspondence to: Dr Youcheng Zhang, The Second Department of General Surgery, Lanzhou University Second Hospital, 82 Cuiyingmen, Lanzhou, Gansu 730030, P.R. China

E-mail: youchengzhang@yandex.com

Key words: colorectal cancer, ginsenoside Rh1, migration, invasion, tumor growth
MAPK signaling pathway inactivation. Therefore, Rh1 may effectively inhibit the development of CRC as an anticancer drug, and may have a supporting effect during CRC treatment.

\section{Introduction}

Colorectal cancer (CRC) is one of the most common types of cancer in men and women, and the third leading cause of cancer-associated mortality in the United States (1). Age is the most significant risk factor (2), and as more individuals shift to a western diet and lifestyle, the incidence of CRC increases (3). Up to 5\% of all CRC cases are caused by hereditary syndromes, which include polyposis and nonpolyposis CRCs (4,5). Endoscopic polypectomy is an effective method to reduce the incidence and mortality of early-stage CRC (6), but the majority of patients are diagnosed at an advanced stage. Out of all patients with CRC, 35-55\% develop hematogenous liver metastasis (7). The 5-year survival rate is $\sim 90 \%$ for patients with early-stage CRC, but $<10 \%$ in patients with distant metastases (8). Therefore, it is critical to seek effective anticancer drugs for the treatment of CRC; however, the exact mechanisms of anticancer drugs in CRC are largely unknown.

Ginseng (the root of Panax ginseng C.A. Meyer) is a valued traditional medicinal herb found in China and Korea, which is widely used for its health benefits, particularly in these countries (9). Ginsenoside Rh1 (Rh1), found in red ginseng, is a metabolite of the major ginsenosides Re and $\mathrm{Rg} 1$, formed by intestinal microbiota following the oral ingestion of ginseng $(10,11)$. Rh1 has been reported to possess anti-allergic, anti-inflammatory, anti-aging, antioxidant and antitumor activity (12-14). Rh1 may also increase learning and memory capacity, as well as hippocampal excitability $(15,16)$. Additionally, other pharmacological effects have been noted, including myocardial injury (17) and obesity prevention (18), as well as antiplatelet effects (19). Additionally, Rh1 induces anticancer effects in several tumor cells, including human hepatocellular carcinoma (20), astroglioma (21) and acute monocytic leukemia cells (22).

Although several studies have investigated the anticancer effects of Rh1, to the best of our knowledge, there have been no reports regarding the effects of Rh1 in CRC to date. The underlying mechanisms of Rh1 on CRC migration and invasion remain unknown. Therefore, in the present study, the 
regulation of $\mathrm{CRC}$ invasion and migration by Rh1 was investigated in vitro and in vivo.

\section{Materials and methods}

Cell culture. The human CRC cell line SW620 was purchased from the Type Culture Collection of the Chinese Academy of Sciences. Cells were cultured in RPMI-1640 medium (Gibco; Thermo Fisher Scientific, Inc.) supplemented with $10 \%$ heat-inactivated fetal bovine serum (FBS; Gibco; Thermo Fisher Scientific, Inc.), $1 \%$ streptomycin and $1 \%$ penicillin (all from Invitrogen; Thermo Fisher Scientific, Inc.). The cultured cells were incubated at $37^{\circ} \mathrm{C}$ with $5 \% \mathrm{CO}_{2}$.

Analysis of cell viability and cell proliferation. Ginsenoside Rh1 (purity $>97 \%$ ) was purchased from Chengdu Must Bio-Technology Co., Ltd. (cat. no. A0240). The effects of Rh1 on SW620 cell viability and proliferation were determined by Cell Counting Kit-8 (CCK-8; Dojindo Molecular Technologies, Inc.) assays. Briefly, SW620 cells in the logarithmic growth phase were seeded into 96 -well plates at a density of $2 \times 10^{3}$ cells/well. Next, for examining cell viability, cells were treated with Rh1 at concentrations of 0,50 or $100 \mu \mathrm{M}$ at $37^{\circ} \mathrm{C}$ for 24 or $48 \mathrm{~h}$, and cells were treated with 0,50 or $100 \mu \mathrm{M}$ $\mathrm{Rh} 1$ at $37^{\circ} \mathrm{C}$ for $0,12,24$ and $48 \mathrm{~h}$ to examine cell proliferation. Untreated cell served as the control group. Then, $10 \mu \mathrm{l}$ CCK-8 reagent was added to each well and cells were incubated at $37^{\circ} \mathrm{C}$ with $5 \% \mathrm{CO}_{2}$ for another $2 \mathrm{~h}$. The absorbance of each well was measured at $450 \mathrm{~nm}$ using a microplate reader (Thermo Fisher Scientific, Inc.).

Cell migration assay. Cell migration was determined by a wound healing test. Cells $\left(5 \times 10^{5}\right.$ cells/well $)$ were seeded into 6 -well plates and incubated at $37^{\circ} \mathrm{C}$ until $>90 \%$ confluence was reached. Cell monolayers were carefully scratched using a $10-\mu 1$ sterile plastic pipette tip to make an artificial wound. The floating cell debris was rinsed twice with PBS. Subsequently, fresh serum-free RPMI-1640 medium containing different concentrations of Rh1 ( 0 or $100 \mu \mathrm{M})$ was added. Images of the wound area were captured at 0 and $24 \mathrm{~h}$ under an inverted light microscope (magnification, x200; Olympus Corporation).

Matrigel invasion assay. Transwell chambers (pore size, $8-\mu \mathrm{m}$; Corning Inc.) were used to examine the cell invasion capacity. The chamber filter was pre-coated with $100 \mu \mathrm{l}$ diluted Matrigel (BD Biosciences). Cell suspensions (200 $\mu \mathrm{l}$; $2 \times 10^{5}$ cells in serum-free RPMI-1640 medium containing 0 or $100 \mu \mathrm{M}$ Rh1) were added to the upper chamber. The bottom chamber was filled with complete RPMI-1640 medium containing $10 \%$ FBS. Following incubation at $37^{\circ} \mathrm{C}$ with $5 \% \mathrm{CO}_{2}$ for $24 \mathrm{~h}$, the remaining cells on the top surface of the filter were removed. The invasive cells on the lower surface of the filter were fixed in $4 \%$ paraformaldehyde for $10 \mathrm{~min}$ and stained in $0.1 \%$ crystal violet for $15 \mathrm{~min}$ both at room temperature. The invasive cells were imaged and counted using a light microscope (Olympus Corporation) at x200 magnification in five random fields.

Reverse transcription-quantitative PCR (RT-qPCR). SW620 cells $\left(2 \times 10^{5}\right)$ in the logarithmic growth phase were seeded in 6-well plates until 90\% confluence was reached. Subsequently, they were treated with 0 or $100 \mu \mathrm{M} \mathrm{Rh} 1$ at $37^{\circ} \mathrm{C}$ for $24 \mathrm{~h}$. Total RNA from cells was extracted using TRIzol ${ }^{\circledR}$ reagent (Invitrogen; Thermo Fisher Scientific, Inc.). cDNA synthesis was performed using a PrimeScript ${ }^{\mathrm{TM}}$ RT reagent kit with gDNA Eraser (Takara Biotechnology Co., Ltd.). RT reaction conditions were as follows: $37^{\circ} \mathrm{C}$ for $15 \mathrm{~min}$ followed by $85^{\circ} \mathrm{C}$ for 5 sec. qPCR was performed using SYBR Premix Ex Taq II (Tli RNaseH Plus; Takara Biotechnology Co., Ltd.), according to manufacturer's protocol, on an ABI PRISM 7500 Real-Time PCR system (Applied Biosystems; Thermo Fisher Scientific, Inc.). The PCR conditions were as follows: Initial denaturation at $95^{\circ} \mathrm{C}$ for $30 \mathrm{sec}$, followed by 40 cycles of denaturation at $95^{\circ} \mathrm{C}$ for $5 \mathrm{sec}$ and annealing/extension at $60^{\circ} \mathrm{C}$ for $34 \mathrm{sec}$. The melting curve was analyzed at the end of amplification. The fold change of each gene was calculated using the $2^{-\Delta \Delta \mathrm{Cq}}$ method (23) and normalization to GAPDH. The primers were synthesized by GenScript, and the sequences used were: Matrix metallopeptidase (MMP)1 forward, 5'-AGGACTCCAAGG TAGACACAC-3' and reverse, 5'-TTGCCGTTCTTGTAGGTG AACGC-3'; MMP3 forward, 5'-CCTGCTTTGTCCTTTGAT GC-3', and reverse, 5'-TGAGTCAATCCCTGGAAAGTC-3'; tissue inhibitor of metalloproteinases 3 (TIMP3) forward, 5'-AGTTACCCAGCCCTATGA-3' and reverse, 5'-GCAAAG GCTTAAACATCT-3'; and GAPDH forward, 5'-GAAGGT GAAGGTCGGAGTC-3' and reverse, 5'-GAAGATGGTGAT GGGATTTC-3'.

Western blot analysis. SW620 cells $\left(2 \times 10^{5}\right)$ treated with 0 or $100 \mu \mathrm{M}$ Rh1 for $24 \mathrm{~h}$ as aforementioned were harvested and lysed in RIPA buffer (Beyotime Institute of Biotechnology). Protein concentration was determined by the bicinchoninic acid (BCA) method using a BCA Protein Assay kit (Beijing Solarbio Science \& Technology Co., Ltd.) according to the manufacturer's protocol. A total of $30 \mu \mathrm{g}$ of protein was separated via 10\% SDS-PAGE. Following electrophoresis, proteins were transferred onto PVDF membranes (Thermo Fisher Scientific, Inc.). Membranes were blocked in TBS with $0.05 \%$ Tween 20 (Beijing Solarbio Science \& Technology Co., Ltd.) containing 5\% skimmed milk at room temperature for $1 \mathrm{~h}$, and subsequently incubated with primary antibodies at $4^{\circ} \mathrm{C}$ overnight. The primary antibodies (all from Abcam) included: Anti-MMP1 (cat. no. ab38929; 1:5,000), anti-MMP3 (cat. no. ab53015; 1:1,000), anti-ERK1+ERK2 (cat. no. ab17942; 1:1,000), anti-phosphorylated (p-)ERK1 + ERK2 (p-T202 + T204; cat. no. ab214362; 1:1,000), anti-P38 (cat. no. ab197348; 1:1,000), anti-p-P38 (p-T180; cat. no. ab178867; 1:1,000 dilution), anti-JNK1+JNK2 (cat. no. ab112501; 1:1,000), anti-p-JNK1 + JNK2 (p-T183 + T185; cat. no. ab4821; 1:1,000), anti-TIMP3 (cat. no. ab39184; 1:1,000) and anti-GAPDH (cat. no. ab181602; 1:10,000). Next, the membranes were incubated with secondary antibody conjugated to horseradish peroxidase (goat anti-rabbit immunoglobulin G; 1:2,000 dilution; cat. no. ab205718; Abcam) for $1 \mathrm{~h}$ at room temperature. The immunopositive bands were visualized using a Pierce ECL Western Blotting kit (Thermo Fisher Scientific, Inc.) according to the manufacturer's protocols. Band intensity was determined with the ImageQuant ${ }^{\mathrm{TM}}$ LAS 4010 biomolecular imager (GE Healthcare Life Sciences) and normalized to GAPDH. 
Nude mouse xenograft model and Rh1 treatment. A total of 6 adult male BALB/c nude mice (4-6 weeks; 20-22 g) were selected for the present study. Nude mice were purchased from Shanghai Experimental Animal Center of the Chinese Academy of Sciences (Shanghai, China). The mice were housed individually in a specific pathogen-free environment with free access to water and food under $26-28^{\circ} \mathrm{C}, 40-60 \%$ humidity and $10 \mathrm{~h} \mathrm{light} / 14 \mathrm{~h}$ dark conditions. The experimental procedures were approved by the Institutional Animal Care and Use Committee of Lanzhou University Second Hospital (Lanzhou, China). Logarithmic growth phase SW620 cells $\left(3 \times 10^{6}\right)$ were suspended in $250 \mu 1$ PBS and Matrigel (1:1 ratio; BD Biosciences) and injected subcutaneously into the dorsal right flank of mice. Mice were randomly divided into control and $\mathrm{Rh} 1$ groups ( 3 mice/group). Mice in the control group were orally administered with $2 \mathrm{ml}$ distilled water/day, while mice in Rh1 group were orally administrated with $20 \mathrm{mg} / \mathrm{kg} / \mathrm{day}$ $\mathrm{Rh} 1$, dissolved in $2 \mathrm{ml}$ distilled water, for 35 consecutive days. Tumor volumes were measured once per week. At day 35, mice were sacrificed by decapitation and the tumors were dissected at $12 \mathrm{~h}$ after the last drug delivery. The tumor length and width were measured with a caliper, and the volume was calculated using the formula: Volume $=0.5 \mathrm{x}$ (length $\mathrm{x}$ width $)^{2}$. Images of the tumors in each group were captured and the tumors were weighed.

Statistical analysis. Statistical analysis was performed using GraphPad Prism version 7 software (GraphPad Software, Inc.). Data are expressed as the means \pm SEM of at least three independent experiments. The differences between two groups were analyzed using a Student's t-test, and the differences among multiple groups were assessed using one-way ANOVA followed by a Newman Keuls post hoc test. $\mathrm{P}<0.05$ was considered to indicate a statistically significant difference.

\section{Results}

Effects of Rhl on the viability and proliferation of CRC cells. To investigate the effects of Rh1 on cell viability and proliferation, SW620 cells were treated with various concentrations $(0,50$ or $100 \mu \mathrm{M})$ of Rh1, and CCK-8 assays were performed. As shown in Fig. 1A, 50 and $100 \mu \mathrm{M}$ Rh1 did not influence cell viability in the treatment groups, compared with in the control group. Furthermore, Rh1 treatment for 24 or $48 \mathrm{~h}$ did not significantly influence cell viability for the same $\mathrm{Rh} 1$ concentrations. These results indicated that Rh1 did not exert significant cytotoxicity on SW620 cells at $0-100 \mu \mathrm{M}$ for 24 or $48 \mathrm{~h}$. However, 50 and $100 \mu \mathrm{M}$ Rh1 significantly inhibited cell proliferation (50 $\mu \mathrm{M}, \mathrm{P}<0.01 ; 100 \mu \mathrm{M}, \mathrm{P}<0.001)$ in the treatment group compared with in the control group (Fig. 1B). The nontoxic concentration of $100 \mu \mathrm{M}$ was selected for subsequent experimentation.

Rhl inhibits the migration and invasion of CRC cells in vitro. To evaluate the effects of Rh1 on cell migration and invasion, SW620 cells were treated with 0 or $100 \mu \mathrm{M}$ Rh1 for $24 \mathrm{~h}$. The wound healing assay demonstrated that Rh1 significantly inhibited wound closure. The percentage of the wound area in the $\mathrm{Rh} 1$ group was significantly greater than that of the control
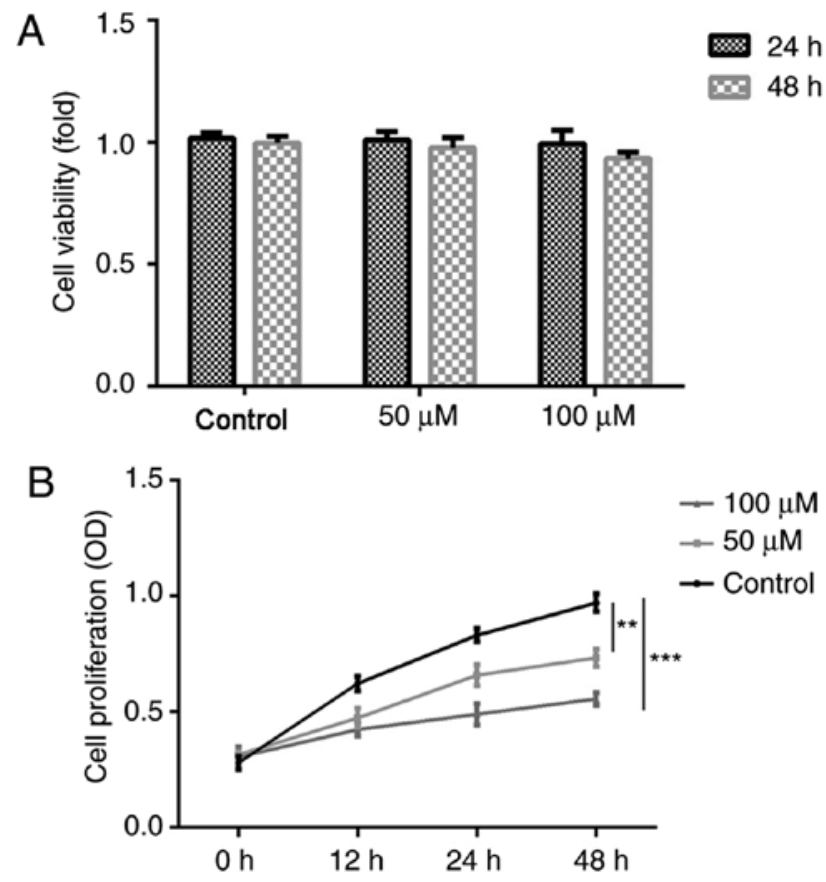

Figure 1. Rh1 has no toxic effect but inhibits proliferation in colorectal cancer cells. (A) SW620 cells were treated with 0,50 or $100 \mu \mathrm{M}$ Rh1 for 24 or $48 \mathrm{~h}$, and cell viability was subsequently measured using a CCK-8 assay. (B) Rh1 $(0,50$ or $100 \mu \mathrm{M})$ was used to treat SW620 cells for $0,12,24$ and $48 \mathrm{~h}$, and a CCK-8 assay was performed to detect cell proliferation. Data are presented as the means \pm SEM. ${ }^{* *} \mathrm{P}<0.01$ and ${ }^{* * *} \mathrm{P}<0.001$ vs. control group. CCK-8, Cell Counting kit-8; OD, optical density; Rh1, ginsenoside Rh1.

group $(\mathrm{P}<0.01$; Fig. 2A). Similarly, the Transwell invasion assay demonstrated that Rh1 treatment significantly decreased the number of invasive cells, compared with the control group $(\mathrm{P}<0.01$; Fig. 2B). These data suggested that Rh1 effectively inhibited the migration and invasion of CRC cells in vitro.

Rh1 suppresses MMP1 and MMP3 expression, increases the expression levels of TIMP3 and inhibits mitogen-activated protein kinase (MAPK) signaling pathway activation. The expression levels of MMP1, MMP3 and TIMP3 were measured in CRC cells via RT-qPCR and western blot analyses, respectively. The results revealed that $\mathrm{Rh} 1$ treatment markedly decreased the mRNA expression levels of MMP1 and MMP3, and increased TIMP3 mRNA expression, compared with the control group $(\mathrm{P}<0.01$; Fig. 3A-C). Consistently, the protein expression levels of MMP1 and MMP3 were significantly decreased, and TIMP3 expression was increased in the Rh1 group ( $\mathrm{P}<0.01$; Fig. 3D-G). Additionally, as presented in Fig. $3 \mathrm{H}$ and $\mathrm{I}$, it was demonstrated that Rh1 significantly decreased the ratios of p-P38/P38, p-ERK1/2/ERK1-2 and $\mathrm{p}-\mathrm{JNK} / \mathrm{JNK}$ compared with the control group $(\mathrm{P}<0.01)$. These results suggested that Rh1 inhibited MAPK signaling.

Inhibitory effects of Rh1 on xenograft tumor growth and $M A P K$ signaling in vivo. To further investigate the antitumor effects of Rh1, a xenograft model of nude mice was established with SW620 cells. Rh1 (0 or $20 \mathrm{mg} / \mathrm{kg}$ ) was orally administered to treat the tumors in mice, and tumor growth was determined. The tumor volume was significantly decreased in the Rh1 group compared with in the control group after 
A
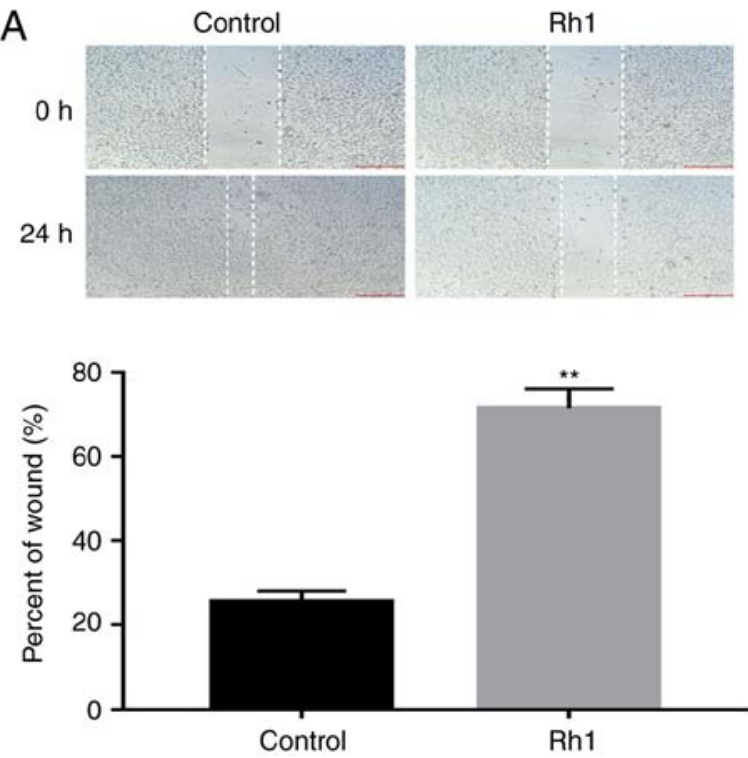

B
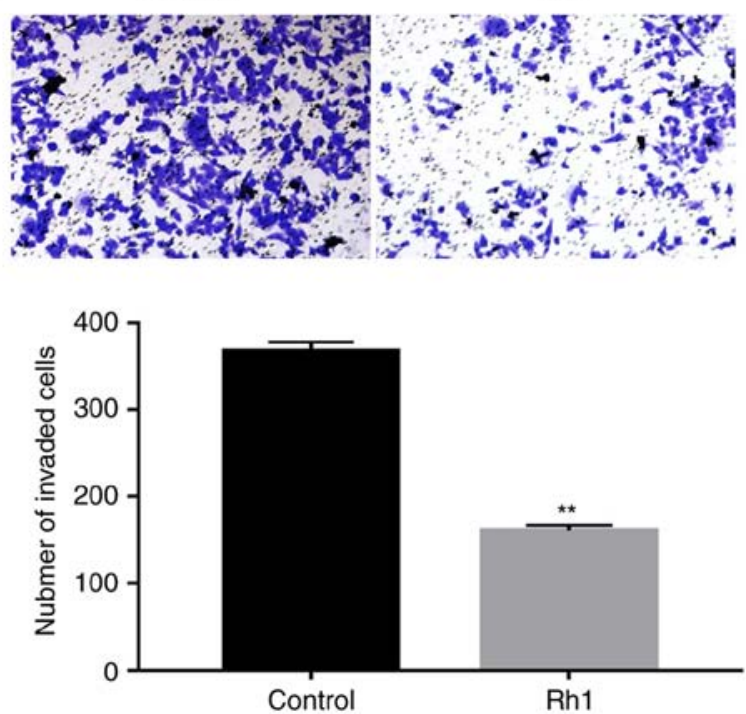

Figure 2. Rh1 reduces the migration and invasion capabilities of colorectal cancer cells. (A) Following treatment of SW620 cells with 0 or $100 \mu \mathrm{M}$ Rh1 for $24 \mathrm{~h}$, cell migration was assessed using a wound healing assay. The percentage of wound width was calculated at $24 \mathrm{~h}$ compared with $0 \mathrm{~h}$. (B) SW620 cells were treated with 0 or $100 \mu \mathrm{M} \mathrm{Rh1}$, and cell invasion was assessed using a Transwell assay. The invasive cells were imaged and counted. Data are presented as the means \pm SEM. ${ }^{* *} \mathrm{P}<0.01$ vs. control group. Rh1, ginsenoside Rh1.
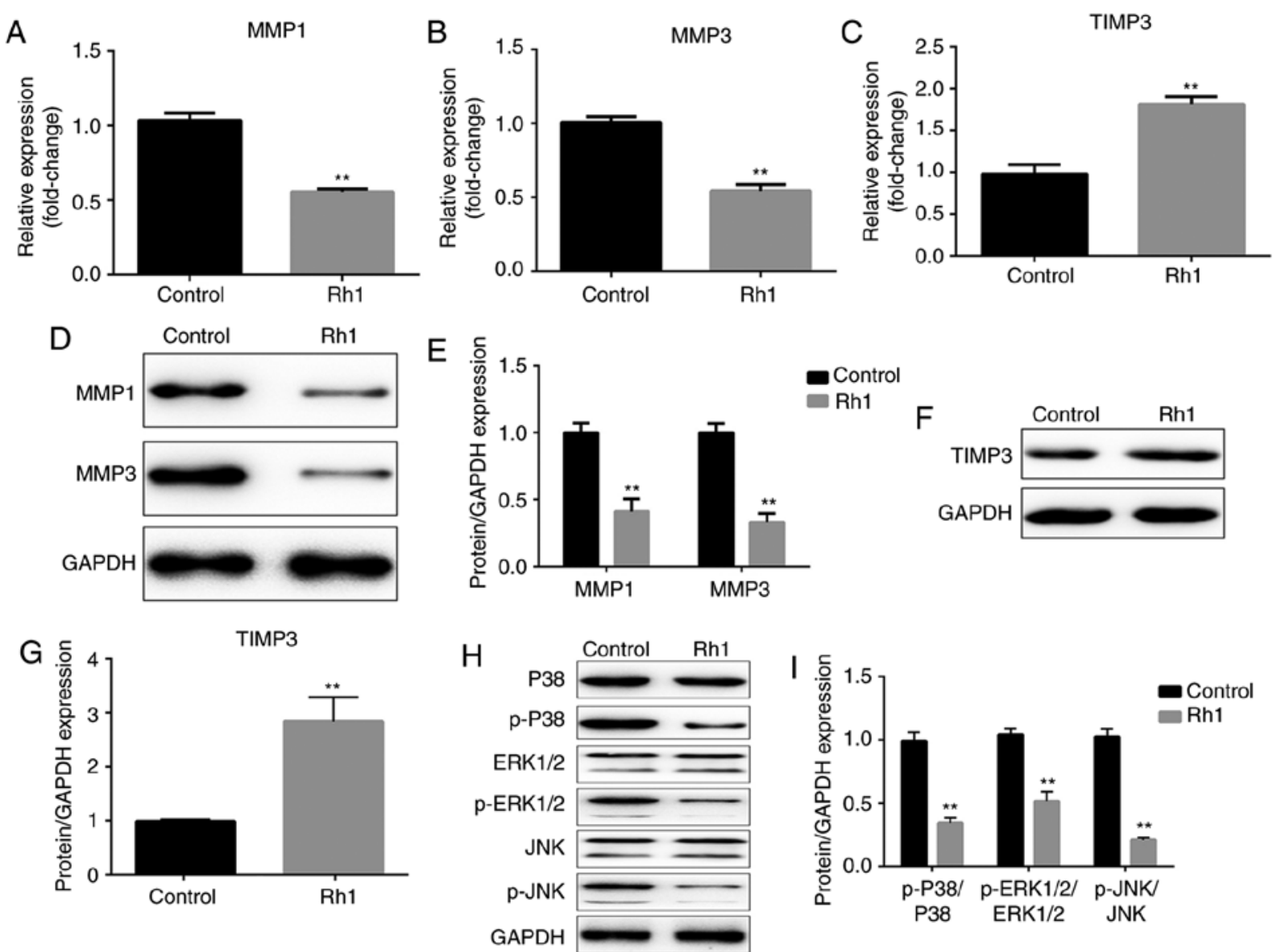

Figure 3. Rh1 decreases the mRNA and protein expression levels of MMP1 and MMP3, enhances TIMP3 expression and inhibits the phosphorylation of ERK1/2, P38 and JNK. mRNA expression levels of (A) MMP1, (B) MMP3 and (C) TIMP3 were detected using reverse transcription-quantitative PCR following exposure of SW620 cells to 0 or $100 \mu \mathrm{M}$ Rh1 for $24 \mathrm{~h}$. (D) Protein expression levels of MMP1 and MMP3 were measured using western blotting. GAPDH was used as an internal control. (E) Fold change of MMP1 and MMP3 protein levels was normalized using GAPDH. (F) Protein expression levels of TIMP3 were detected by western blot analysis. GAPDH was used for normalization. (G) Semi-quantified TIMP3 protein expression. (H) Protein expression levels of P38, p-P38, ERK1/2, p-ERK1/2, JNK and p-JNK were assessed using western blotting. GAPDH was used as an internal control. (I) Relative protein expression levels of p-P38, p-ERK1/2 and p-JNK were compared with their total amount. Data are presented as the means \pm SEM. ${ }^{* *} \mathrm{P}<0.01$ vs. control group. MMP, matrix metallopeptidase; p-, phosphorylated-; Rh1, ginsenoside Rh1; TIMP3, tissue inhibitor of metalloproteinases 3. 

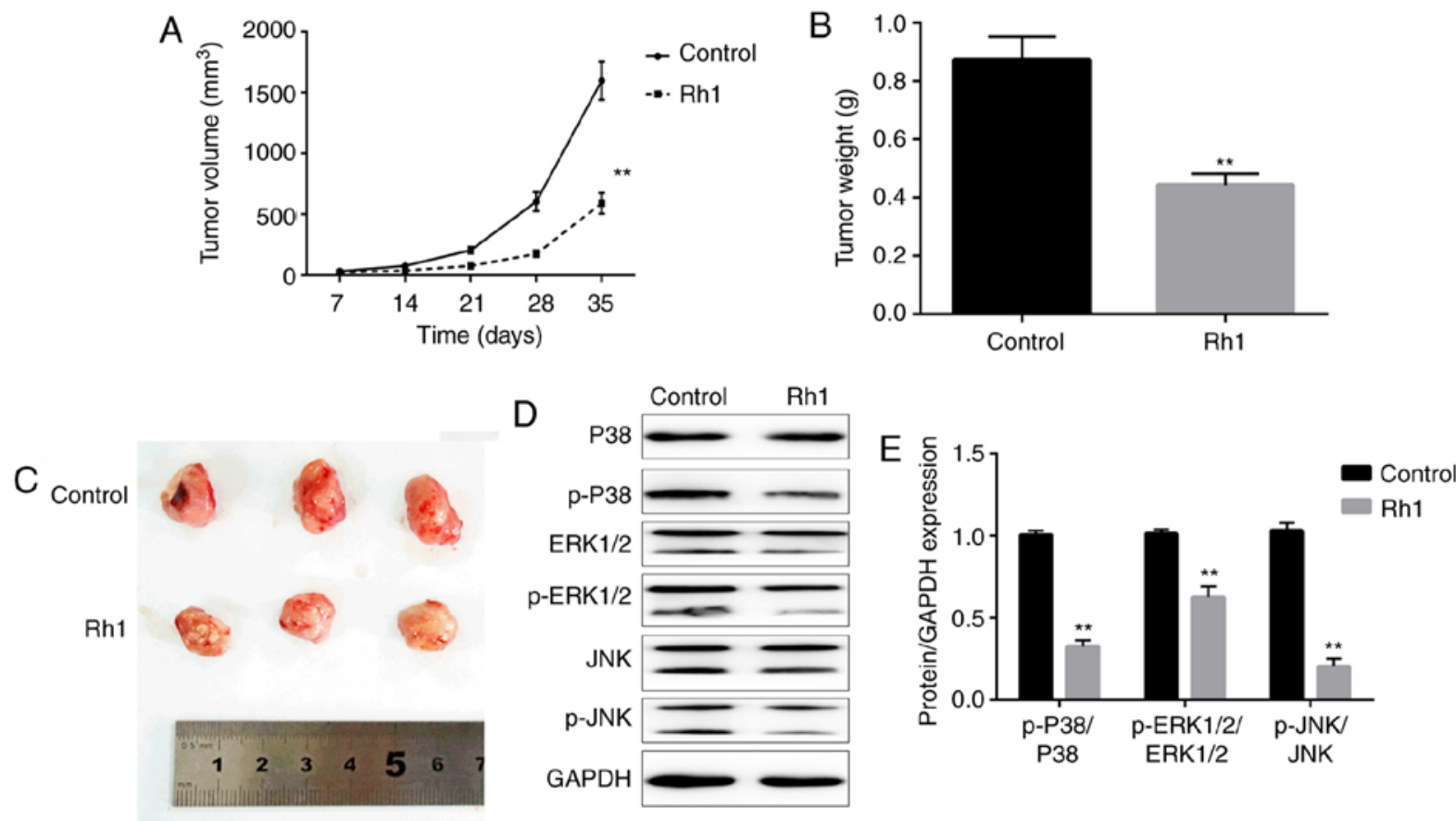

Figure 4. Rh1 inhibits tumor growth and the mitogen-activated protein kinase signaling pathway in vivo. (A) Tumor volumes were determined every week following Rh1 treatment. (B) Tumor weights were measured when the tumors were dissected. (C) Tumors in control and Rh1 groups were photographed following resection. (D) Protein expression levels of p-P38, P38, p-ERK1/2, ERK1/2, p-JNK and JNK were determined by western blotting. GAPDH was used for normalization. (E) Analysis of western blotting. Data are presented as the means \pm SEM. ${ }^{* *} \mathrm{P}<0.01$ vs. control group. p-, phosphorylated-; Rh1, ginsenoside $\mathrm{Rh} 1$.

35 days $(\mathrm{P}<0.01$; Fig. 4A). When the tumors were harvested, the tumor weights were measured. Rh1 treatment significantly decreased the tumor weight, compared with the control group ( $\mathrm{P}<0.01$; Fig. 4B). Additionally, tumor size was markedly decreased in the Rh1 group compared with that in the control group (Fig. 4C). These results suggested that Rh1 inhibited tumor growth in vivo. Additionally, whether Rh1 regulates the MAPK signaling pathway in vivo remains unclear. The ratios of p-P38/P38, p-ERK1/2/ERK1-2 and p-JNK/JNK were significantly downregulated in Rh1 treated mice tumor tissues compared with in tissues from the control group $(\mathrm{P}<0.01$; Fig. 4D and E).

\section{Discussion}

The present study revealed that different concentrations of Rh1 exhibited no toxicity in CRC cells. Rh1 $(100 \mu \mathrm{M})$ significantly inhibited the proliferation, migration and invasion of $\mathrm{CRC}$ cells in vitro, and $20 \mathrm{mg} / \mathrm{kg} \mathrm{Rh} 1$ inhibited tumor growth in vivo.

$\mathrm{Rh} 1$ is a hydrolysis product that reaches the systemic circulation following ginseng ingestion (24), and has been reported to exhibit certain biological activities, including anti-allergic, anti-inflammatory and antitumor activities (12-14). Previous studies have revealed that $\mathrm{Rh} 1$ is involved in cell viability and proliferation. For example, Rh1 inhibits the proliferation of non-alcoholic fatty liver cells (25). Conversely, Wang et al (26) revealed that Rh1 has no effect on human peripheral blood mononuclear cell proliferation up to $100 \mathrm{mg} / \mathrm{l}$. In addition, the cytotoxicity in neuronal cells is not affected by different concentrations of Rh1 (27). Rh1 at the concentrations of
0-100 $\mu \mathrm{M}$ was not toxic to CRC cells in the present study. However, cell proliferation was significantly suppressed by $\mathrm{Rh} 1$ in a dose-dependent manner. These findings suggested that Rh1 suppressed tumor progression partially due to the inhibition of cell proliferation rather than due to toxic effects. Therefore, a nontoxic concentration was selected for a more accurate assessment of CRC cell migration and invasion.

Migration and invasion are major obstacles in the treatment of cancer, which induce poor prognosis and affect patient survival (28). Previous studies have revealed that Rh1 inhibits human cancer migration and invasion: For example, Rh1 exerts inhibitory effects on migration and invasion by suppressing MMP1, MMP3 and MMP9 expression in human astroglioma (21). Additionally, Rh1 inhibits THP-1 acute monocytic leukemia cell migration and invasion (22). Similarly, the results of the present study demonstrated that Rh1 inhibited CRC cell migration and invasion. However, the molecular mechanisms underlying the inhibition of migration and invasion remain unclear.

MMPs, including MMP1 and MMP3, serve an important role in tumor progression, and are involved in tumor metastasis processes, including angiogenesis, migration and invasion (29). High expression levels of MMP1 are associated with lymph node metastasis, and promote tumor growth and metastasis in esophageal squamous cell carcinoma (30). In CRC, MMP1 is a prognostic indicator for hematogenous metastasis (31). MMP3 is a tumor promoter involved in tumorigenesis and metastasis, which promotes tumor cell migration and invasion (32). TIMPs inhibit activated MMPs, keeping the balance of TIMPs and MMPs (33). TIMP3 has been reported to be associated with anticancer capability, and regulates cell migration 
and invasion in osteosarcoma (34), cervical cancer (35) and esophageal squamous cell carcinoma (36). In CRC, TIMP3 is downregulated in tumor tissues and inhibits cell migration and invasion (37). The present study measured the expression levels of MMP1 and MMP3, which were decreased following Rh1 treatment. Additionally, Rh1 treatment led to an increase in the expression levels of TIMP3. Thus, it was inferred that Rh1 suppressed CRC cell migration and invasion, at least partially, via suppressing MMP1 and MMP3 expression and promoting TIMP3 expression.

The MAPK signaling pathway consists of four independent cascades. The terminal kinases of these cascades include ERK, Big MAPK-1, JNK and P38 (38). The MAPK signaling pathways link extracellular signals to the machinery that controls basic cellular processes, including proliferation, differentiation, invasion, migration and apoptosis $(39,40)$. A previous study revealed that Rh1 suppresses MMP1 expression via inhibition of MAPK signaling (20). In addition, Rh1 inhibited the migration and invasion of acute monocytic leukemia cells by inactivating the MAPK signaling pathway (22). The present study revealed that Rh1 inhibited the phosphorylation of ERK1/2, p38 and JNK in SW620 cells and tumor-bearing mice tissues, which suggested that Rh1 inhibited the activation of the MAPK signaling pathway not only in vitro but also in vivo. From this, it was concluded that Rh1 may have suppressed CRC cell migration and invasion via MAPK signaling pathway inactivation.

Furthermore, a xenograft model was established to investigate the effects of Rh1 on tumor growth in mice. It was identified that Rh1 reduced tumor volume and weight, indicating that Rh1 inhibited tumor growth in vivo. To the best of our knowledge, this was the first study demonstrating that Rh1 exerted anticancer activity in CRC in vivo.

In conclusion, the present study demonstrated that Rh1 significantly reduced CRC cell proliferation, migration and invasion. Rh1 exerted anticancer activity, potentially through inhibiting MMP1 and MMP3 expression, increasing TIMP3 expression, and MAPK signaling pathway inactivation. Furthermore, Rh1 inhibited tumor growth and the MAPK signaling pathway in vivo. These findings indicated that Rh1 has potential for development into a novel drug for adjuvant therapy of CRC.

\section{Acknowledgements}

Not applicable.

\section{Funding}

No funding was received.

\section{Availability of data and materials}

All data generated or analyzed during this study are included in this published article.

\section{Authors' contributions}

XL and YCZ designed the study. XL, XX, AS, JG and YWZ performed the experiments and analyzed data. XL mainly wrote the manuscript and YCZ revised it. All authors have read and approved the final manuscript.

\section{Ethics approval and consent to participate}

The experimental procedures were approved by the Institutional Animal Care and Use Committee of Lanzhou University Second Hospital (Lanzhou, China).

\section{Patient consent for publication}

Not applicable.

\section{Competing interests}

The authors declare that they have no competing interests.

\section{References}

1. Siegel RL, Miller KD and Jemal A: Cancer statistics, 2016. CA Cancer J Clin 66: 7-30, 2016.

2. Binefa G, Rodríguez-Moranta F, Teule A and Medina-Hayas M: Colorectal cancer: From prevention to personalized medicine. World J Gastroenterol 20: 6786-6808, 2014.

3. Brody H: Colorectal cancer. Nature 521 (Suppl): S1, 2015.

4. Balaguer F: Hereditary and familial colorectal cancer. Gastroenterol Hepatol Suppl 3: 77-84, 2014.

5. Vasen HF, Tomlinson I and Castells A: Clinical management of hereditary colorectal cancer syndromes. Nat Rev Gastroenterol Hepatol 12: 88-97, 2015.

6. Pellisé M: Colonoscopy in the screening, follow-up and treatment of colorectal cancer and precursor lesions. Gastroenterol Hepatol 38 (Suppl 1): S71-S77, 2015 (In Spanish).

7. Akgül Ö, Çetinkaya E, Ersöz Ş and Tez M: Role of surgery in colorectal cancer liver metastases. World J Gastroenterol 20: 6113-6122, 2014

8. Ting WC, Chen LM, Pao JB, Yang YP, You BJ, Chang TY, Lan YH, Lee HZ and Bao BY: Common genetic variants in Wnt signaling pathway genes as potential prognostic biomarkers for colorectal cancer. PLoS One 8: e56196, 2013.

9. Xiang YZ, Shang HC, Gao XM and Zhang BL: A comparison of the ancient use of ginseng in traditional Chinese medicine with modernpharmacological experiments and clinical trials. Phytother Res 22: 851-858, 2008.

10. Lee SM, Bae BS, Park HW, Ahn NG, Cho BG, Cho YL and Kwak YS: Characterization of Korean red ginseng (Panax ginseng Meyer): History, preparation method and chemical composition. J Ginseng Res 39: 384-391, 2015.

11. Ko SR, Suzuki Y, Choi KJ and Kim YH: Enzymatic preparation of genuine prosapogenin, 20(S)-ginsenoside Rh1, from ginsenosides Re and Rg1. Biosci Biotechnol Biochem 64: 2739-2743, 2000.

12. Park EK, Choo MK, Han MJ and Kim DH: Ginsenoside Rh1 possesses antiallergic and anti-inflammatory activities. Int Arch Allergy Immunol 133: 113-120, 2004.

13. Jiang Y, Liu W, Wang XM, Zhong GG, Zhang WJ, Chen L, Zhan S, Qi H, Zhao CY, Ma XY, et al: Calcium channel blockade and anti-free-radical actions of panaxatriol saponins in cultured myocardiocytes. Zhongguo Yao Li Xue Bao 17: 138-141, 1996.

14. Cheng Y, Shen LH and Zhang JT: Anti-amnestic and anti-aging effects of ginsenoside $\mathrm{Rg} 1$ and $\mathrm{Rb} 1$ and its mechanism of action. Acta Pharmacol Sin 26: 143-149, 2005.

15. Wang YZ, Chen J, Chu SF, Wang YS, Wang XY, Chen NH and Zhang JT: Improvement of memory in mice and increase of hippocampal excitability in rats by ginsenoside Rg1's metabolites ginsenoside Rh1 and protopanaxatriol. J Pharmacol Sci 109: 504-510, 2009.

16. Hou J, Xue J, Lee M, Yu J and Sung C: Long-term administration of ginsenoside Rh1 enhances learing and memory by promoting cell survival in the mouse hippocampus. Int J Mol Med 33: 234-240, 2014.

17. Gai Y, Ma Z, Yu X, Qu S and Sui D: Effect of ginsenoside Rh1 on myocardial injury and heart function in isoproterenol-induced cardiotoxicity in rats. Toxicol Mech Methods 22: 584-591, 2012. 
18. Gu W, Kim KA and Kim DH: Ginsenoside Rh1 ameliorates high fat diet-induced obesity in mice by inhibiting adipocyte differentiation. Biol Pharm Bull 36: 102-107, 2013.

19. Teng CM, Kuo SC, Ko FN, Lee JC, Lee LG, Chen SC and Huang TF: Antiplatelet actions of panaxynol and ginsenosides isolated from ginseng. Biochim Biophys Acta 990: 315-320, 1989.

20. Yoon JH, Choi YJ and Lee SG: Ginsenoside Rh1 suppresses matrix metalloproteinase-1 expression through inhibition of activator protein-1 and mitogen-activated protein kinase signaling pathway in human hepatocellular carcinoma cells. Eur J Pharmacol 679: 24-33, 2012.

21. Jung JS, Ahn JH, Le TK, Kim DH and Kim HS: Protopanaxatriol ginsenoside Rh1 inhibits the expression of matrix metalloproteinases and the in vitro invasion/migration of human astroglioma cells. Neurochem Int 63: 80-86, 2013.

22. Choi YJ, Yoon JH, Cha SW and Lee SG: Ginsenoside Rh1 inhibits the invasion and migration of THP-1 acute monocytic leukemia cells via inactivation of the MAPK signaling pathway. Fitoterapia 82: 911-919, 2011

23. Livak KJ and Schmittgen TD: Analysis of relative gene expression data using real-time quantitative PCR and the 2(-Delta Delta C(T)) method. Methods 25: 402-408, 2001.

24. Lai L, Hao H, Liu Y, Zheng C, Wang Q, Wang G and Chen X: Characterization of pharmacokinetic profiles and metabolic pathways of 20(S)-ginsenoside Rh1 in vivo and in vitro. Planta Med 75: 797-802, 2009.

25. Chen XJ, Liu WJ, Wen ML, Liang H, Wu SM, Zhu YZ, Zhao JY Dong XQ, Li MG, Bian L, et al: Ameliorative effects of Compound $\mathrm{K}$ and ginsenoside Rh1 on non-alcoholic fatty liver disease in rats. Sci Rep 7: 41144, 2017.

26. Wang Y, Wang BX, Liu TH, Minami M, Nagata T and Ikejima T: Metabolism of ginsenoside $\operatorname{Rg} 1$ by intestinal bacteria. II. Immunological activity of ginsenoside Rg1 and Rh1. Acta Pharmacol Sin 21: 792-796, 2000.

27. Li XF, Lui CN, Jiang ZH and Ken YK: Neuroprotective effects of ginsenosides Rh1 and Rg2 on neuronal cells. Chin Med 6: 19, 2011.

28. Kramer N, Walzl A, Unger C, Rosner M, Krupitza G, Hengstschläger $\mathrm{M}$ and Dolznig $\mathrm{H}$ : In vitro cell migration and invasion assays. Mutat Res 752: 10-24, 2013.

29. Deryugina EI and Quigley JP: Matrix metalloproteinases and tumor metastasis. Cancer Metastasis Rev 25: 9-34, 2006.

30. Liu M, Hu Y, Zhang MF, Luo KJ, Xie XY, Wen J, Fu JH and Yang H: MMP1 promotes tumor growth and metastasis in esophageal squamous cell carcinoma. Cancer Lett 377: 97-104, 2016.
31. Sunami E, Tsuno N, Osada T, Saito S, Kitayama J, Tomozawa S, Tsuruo T, Shibata Y, Muto T and Nagawa H: MMP-1 is a prognostic marker for hematogenous metastasis of colorectal cancer. Oncologist 5: 108-114, 2000.

32. Chu C, Liu X, Bai X, Zhao T, Wang M, Xu R, Li M, Hu Y, Li W, Yang L, et al: MiR-519d suppresses breast cancer tumorigenesis and metastasis via targeting MMP3. Int J Biol Sci 14: 228-236, 2018.

33. Jackson HW, Defamie V, Waterhouse P and Khokha R: TIMPs: Versatile extracellular regulators in cancer. Nat Rev Cancer 17 38-53, 2017.

34. Han XG, Li Y, Mo HM, Li K, Lin D, Zhao CQ, Zhao J and Tang TT: TIMP3 regulates osteosarcoma cell migration, invasion and chemotherapeutic resistances. Tumour Biol 37: 8857-8867, 2016.

35. Zhang Z, Wang J, Wang X, Song W, Shi Y and Zhang L: MicroRNA-21 promotes proliferation, migration and invasion of cervical cancer through targeting TIMP3. Arch Gynecol Obstet 297: 433-442, 2018.

36. Liu W, Li M, Chen X, Zhang D, Wei L, Zhang Z, Wang S, Meng L, Zhu S and Li B: MicroRNA-373 promotes migration and invasion in human esophageal squamous cell carcinoma by inhibiting TIMP3 expression. Am J Cancer Res 6: 1-14, 2015.

37. Lin H, Zhang Y, Wang H, Xu D, Meng X, Shao Y, Lin C, Ye Y, Qian $\mathrm{H}$ and Wang S: Tissue inhibitor of metalloproteinases-3 transfer suppresses malignant behaviors of colorectal cancer cells. Cancer Gene Ther 19: 845-851, 2012.

38. Cossa G, Gatti L, Cassinelli G,Lanzi C,Zaffaroni N and Perego P. Modulation of sensitivity to antitumor agents by targeting the MAPK survival pathway. Curr Pharm Des 19: 883-894, 2013

39. Burotto M, Chiou VL, Lee JM and Kohn EC: The MAPK pathway across different malignancies: A new perspective. Cancer 120: 3446-3456, 2014.

40. Yoon JH, Choi YJ, Cha SW and Lee SG: Anti-metastatic effects of ginsenoside Rd via inactivation of MAPK signaling and induction of focal adhesion formation. Phytomedicine 19: 284-292, 2012.

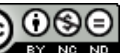

\footnotetext{
This work is licensed under a Creative Commons Attribution-NonCommercial-NoDerivatives 4.0 International (CC BY-NC-ND 4.0) License.
} 